Research, Society and Development, v. 9, n. 9, e119996319, 2020

(CC BY 4.0) | ISSN 2525-3409 | DOI: http://dx.doi.org/10.33448/rsd-v9i9.6319

O esporte na vida escolar: um estudo a partir das experiências de acadêmicos de

\title{
Educação Física
}

Sports in school life: a study of the personal experience of Physical Education academics

EI deporte en la vida escolar: un estudio basado en las experiencias académicas de los estudiantes de Educación Física

Recebido: 04/07/2020 | Revisado: 11/07/2020 | Aceito: 06/08/2020 | Publicado: 14/08/2020

João Márcio Fialho Sampaio

ORCID: https://orcid.org/0000-0003-1458-4011

Universidade Regional do Cariri, Brasil

E-mail: jmarciofisam@gmail.com

José Cícero Cabral de Lima Júnior

ORCID: https://orcid.org/0000-0002-4354-4214

Universidade Regional do Cariri, Brasil

E-mail: junior_flag@hotmail.com

Paulo Rogério Barbosa do Nascimento

ORCID: https://orcid.org/0000-0002-1580-3311

Universidade Regional do Cariri, Brasil

E-mail: paulorogerio.nascimento@urca.br

Lucas Vieira de Lima Silva

ORCID: https://orcid.org/0000-0003-3924-7302

Universidade Regional do Cariri, Brasil

E-mail: lucas.silva@urca.br

Janayna Samara Alves da Silva

ORCID: https://orcid.org/0000-0003-1921-2380

Universidade Regional do Cariri, Brasil

E-mail: janaynasamaraalves@yahoo.com.br

Samara Mendes de Sousa

ORCID: https://orcid.org/0000-0002-5429-3844

Universidade Regional do Cariri, Brasil

E-mail: samaramendes.185@outlook.com

Lázaro Ranieri de Macêdo

ORCID: https://orcid.org/0000-0002-0122-2508 
Universidade Regional do Cariri, Brasil

E-mail: lazaroraniere@gmail.com

Cleiton Félix de Sousa

ORCID: https://orcid.org/0000-0003-3887-4849

Universidade Regional do Cariri, Brasil

E-mail: kleitonfelix55@gmail.com

\title{
Resumo
}

O objetivo deste estudo é identificar, a partir das lembranças de acadêmicos de Educação Física, as práticas esportivas a que tiveram acesso na escola básica. Participaram da pesquisa 102 acadêmicos com idades entre 18 e 35 anos, sendo 52 do sexo feminino e 50 do sexo masculino. Os dados foram obtidos mediante aplicação de questionário, os quais foram analisados a partir de uma específica classificação dos esportes. Observou-se que as maiores vivências ficaram restritas a duas lógicas esportivas: esportes de invasão e esportes de rede divisória, com predominância de um tipo de modalidade dentro de cada grupo: Futsal e Voleibol. Constatou-se que, embora o conteúdo dos esportes seja o mais utilizado nas aulas de Educação Física, os participantes da pesquisa não estudaram a diversidade contida no tema Esporte durante a escolaridade básica.

Palavras-chave: Escola; Esporte; Experiências; Educação física; Ensino.

\begin{abstract}
The objective of this study is to identify, from the memories of Physical Education academics, the sports practices they had access to in primary and secondary school. We selected 102 academics, between 18 and 35 years old, 52 females and 50 males. The data were obtained through a questionnaire and analyzed through a specific sports classification. We identified that most of the experiences were restricted to two types of sports: invasion sports and net sports; with the predominance of one sport within each group: Futsal and Volleyball. We found that, although the content of the sports is most used in Physical Education classes, the participants of the study did not study the diversity within the field of Sports in school.
\end{abstract}

Keywords: School; Sports; Experiences; Physical education; Teaching.

\section{Resumen}

El objetivo de este estudio es identificar, a partir de los recuerdos de los estudiantes de Educación Física, las prácticas deportivas a las que tuvieron acceso en la escuela básica. 102 
estudiantes participaron en la investigación, con edades comprendidas entre 18 y 35 años, 52 de los cuales eran mujeres y 50 hombres. Los datos se obtuvieron mediante la aplicación de un cuestionario, los cuales se analizaron en función de una clasificación específica de los deportes. Se observó que las más grandes experiencias se restringieron a dos lógicas deportivas: deportes de invasión y deportes de red divisoria, con predominio de un tipo de modalidad dentro de cada grupo: fútbol sala y voleibol. Se descubrió que, aunque el contenido deportivo es el más utilizado en las clases de Educación Física, los participantes de la investigación no estudiaron la diversidad contenida en el tema Deporte durante la educación básica.

Palabras clave: Escuela; Deporte; Experiencias; Educación física; Enseñanza.

\section{Introdução}

O esporte é um fenômeno histórico e sociocultural que pode ser analisado sob diferentes dimensões, olhares e possibilidades. É uma prática relevante na Educação Física (EF) e como conteúdo histórico é passível de (re) interpretações. Foi a partir da década de 1980 do século XX, contudo, que se passou, mais enfaticamente, a suscitar críticas e proposições em produções científicas da área, especialmente quanto a sua atuação como atividade na/da escola.

Sua visão esportivista no campo da Educação Física escolar nas décadas de 1970 e 1980 do século XX era criticada, pois estava baseada no alto rendimento esportivo e na busca por talentos dentro do contexto escolar. Procurou-se, então, refletir sobre o esporte escolar em termos da formação humana, cuja questão estava vinculada às abordagens metodológicas produzidas no campo da Educação Física Escolar (EFE) (Darido \& Sanches Neto, 2005).

O esporte, como uma categoria de estudo, é diversificado, multifacetado e polissêmico. São diversificadas as suas modalidades, assim como os sentidos e significados que lhe são atribuídos. Ademais, é um negócio rentável no mercado de bens simbólicos e materiais, chegando a ser evidenciado pelo Programa das Nações Unidas para o Desenvolvimento (PNUD, 2017) como importante ferramenta para o desenvolvimento social, especialmente na Educação. A atividade ainda tem forte vínculo com aspectos da socialização e saúde do ser humano.

Nas últimas décadas vários debates foram realizados no sentido de perceber ou significar a EF como um componente curricular na escola, surgindo no horizonte a necessidade de sua ressignificação. Desvinculava-se, assim, a sua imagem de espaço escolar 
para atividades livres ou da simples "hora de jogar futebol". Paralelamente, ocorreram estudos e proposições sobre os conteúdos da EF, ampliando-se no Esporte as possibilidades de sentido e significado como parte do rol de conteúdos escolares.

Embora as esperanças e as mudanças não fossem tão impactantes na área da EF, Fensterseifer e Silva (2011), além de outros estudiosos que fazem parte da Rede Internacional de Investigação Pedagógica em Educação Física Escolar (REIIPEFE), têm constatado um fenômeno preocupante, chamado "desinvestimento docente". O fenômeno revela uma espécie de cultura escolar em EF, em que grande parte dos professores tem permanecido sem inovar, limitando a veiculação dos conteúdos àqueles mais tradicionais, como Futsal, Basquete, Voleibol e Handebol (Carlan et al., 2012). O foco dessas práticas esportivas é constituir uma seleção escolar para os jogos escolares e ou permitir uma prática sem significativas intervenções pedagógicas, ou seja, uma espécie de prática desinteressada.

Carlan (2012), em sua tese de doutorado, demonstra como é possível relativizar a significação da EF. O pesquisador desenvolveu um estudo de caso junto a um professor de EF com perfil de investimento docente, que revelou o tratamento pedagógico do esporte no âmbito cultural e não somente no âmbito instrumental. É o esporte como conteúdo sendo pedagogicamente estudado, numa articulação com o fundamento epistêmico. Conforme o pesquisador, o professor colaborador da pesquisa rompeu com a dicotomia teoria/prática.

O perfil inovador do professor de EF está atrelado a uma série de elementos da cultura escolar. Essa teoria constitui um elemento animador que pode ser visualizado na pesquisa de Souza, Nascimento e Fensterseifer (2018), os quais investigaram o fenômeno do investimento e desinvestimento docente vivenciado por uma professora em dois momentos distintos. No período de investimento docente, a professora colaboradora destacou como fator preponderante de sua atuação docente positiva, um currículo organizado para a disciplina, o apoio pedagógico da escola e da Secretaria de Educação, assim como o apoio dos pais dos alunos. Isto contribuiu para que a professora materializasse um currículo com conteúdos diversificados e boas práticas pedagógicas.

Ao ensinar um conteúdo de determinada disciplina escolar faz-se necessário perguntar sobre a especificidade da instituição escolar (que antecede a disciplina, e esta antecede o conteúdo). Neste entendimento, não é possível falar sobre Esporte como conteúdo da EFE sem mencionar a escola e a sua peculiaridade enquanto instituição social (González \& Fensterseifer, 2009; González et al., 2014).

A escola é uma instituição social cujo objetivo está atrelado a processos formativos sistematizados (Brandão, 1981; Cortela, 1997). No contexto de um sistema democrático e 
republicano, ela pode ser "entendida [...] como a mais importante instituição na promoção de igualdade dos futuros cidadãos no que se refere às conquistas dos conhecimentos produzidos pela humanidade.” (González et al., 2014, pp. 138-139).

A partir deste entendimento de escola, González e Fensterseifer (2010) estabeleceram dois critérios para compreender a EF como disciplina curricular da escola: a) identificação do seu campo particular de conhecimento sob a responsabilidade específica de um projeto educacional que possibilite uma leitura mais ampliada de mundo; b) explicitação do conjunto de conhecimentos desse componente curricular a serem desenvolvidos de maneira organizada e sistemática no plano curricular da disciplina.

Autores como Kunz (2004), Bracht et al. (2012), Darido (2012), González e Fraga (2012) entre outros, têm definido a EF como o espaço responsável pelo estudo de uma dimensão da cultura humana, denominada "Cultura Corporal de Movimento", na qual o esporte é uma de suas manifestações.

Darido (2012) afirma que para garantir um conhecimento relevante sobre os esportes, além de diversificar as práticas, deve-se aprofundar o conhecimento nas dimensões procedimentais (saber fazer no âmbito regulamentar - técnica e tática), atitudinais (saber conviver - hábitos e atitudes) e nos conteúdos conceituais (capacidade de compreensão interpretação e verbalização sobre a constituição e funcionamento das práticas corporais, seus sentidos e significados socioculturais).

A questão é que, mesmo após décadas de proposições pedagógicas para a Educação Física ainda se vive entre o "ainda não" e o "não mais", ou no "talvez, quem sabe" que não desatualiza o debate sobre o sentido da escola, seu propósito e o significado da presença do esporte na EF escolar.

Ao pensar o esporte como conteúdo da EFE, González e Bracht (2012) partem de uma análise específica daquilo que as modalidades têm de diferente ou comum, ou seja, do conceito de lógica interna dos esportes. Segundo os autores, “o conhecimento da lógica interna permite aos professores fazerem leitura da característica de diversas modalidades esportivas existentes com base nos desafios motores impostos ao praticante.” (González \& Bracht, 2012, p. 19). Diferenciar ou identificar semelhanças entre os conteúdos permite fazer escolhas quanto à possibilidade de experimentações diversificadas desse aspecto da cultura.

Nessa classificação, é preciso considerar o tipo de interação estabelecido com companheiros e adversários: se a prática é sem interação direta com o oponente ou se a prática tem interação direta com ele.

No grupo dos esportes sem interação direta com o oponente, ao se levar em conta o 
resultado do movimento a ser executado, ou seja, "o como fazer", é possível identificar três tipos de lógicas esportivas:

[...] esportes de marca, aqueles baseados na comparação de registro de índices em quilos, metros e segundos. Por exemplo, as provas de atletismo, o remo, o ciclismo, levantamento de peso, entre outros; esportes técnico-combinatórios, que são aqueles esportes que sua característica de pontuação está na estética e na dificuldade de execução do movimento. Por exemplo, a ginástica rítmica, acrobática, a artística, entre outras; e os esportes de precisão, aqueles que seguem um objetivo principal de arremessar, rebater, ou lançar um objeto, procurando acertar um alvo específico imóvel ou em movimento. Por exemplo, golfe, tiro com arco, bocha, entre outros. (González \& Bracht, 2012, p. 22).

O grupo dos esportes de interação direta entre os oponentes se baseia na ação tática, ou seja, "o que fazer, é um elemento intrínseco em todo momento", e objetiva atingir a meta colocada para vencer o jogo, o qual se classifica em quatro tipos:

[...] esportes de combate, que são disputas nas quais o adversário tenta vencer o outro por meio de toques, desequilíbrios, imobilização, etc. Por exemplo, o boxe, esgrima, judô, caratê, entre outros; esportes de campo e taco, que são modalidades com objetivo de rebater a bola o mais longe possível para tentar percorrer o maior número de vezes as bases e, assim, somar pontos. Por exemplo, o tacobol, o beisebol, softbol, entre outros; esportes com rede divisória ou parede de rebote, são aqueles esportes que se lança, arremessa ou bate na bola ou peteca para o espaço adversário. Exemplo disso, o voleibol, tênis, badminton, peteca, entre outros; e por último, os esportes de invasão, que são modalidades onde os atletas tentam ocupar o território da equipe adversária para marcar pontos. Exemplo disso, o futebol, o handebol, o basquete, o rúgbi, entre outros (González \& Bracht, 2012, p. 23).

Essa classificação dos esportes é um esforço de fundamentação da complexidade do conteúdo, uma possibilidade de interpretação da realidade, a qual permite a visão de diversidade, características e particularidades do fenômeno, o que também induz a pensar nas metodologias de ensino.

A partir dessas reflexões e tomadas de posição, pergunta-se: que modalidades esportivas foram vivenciadas por acadêmicos de EF de uma instituição de Ensino Superior localizada na região sul do Ceará, considerando as suas lembranças da Educação Básica?

Para responder a esta questão-problema, definiu-se o seguinte objetivo deste estudo: identificar, a partir das lembranças dos acadêmicos de EF, as práticas esportivas a que tiveram acesso na escola básica.

A motivação do estudo pode ser justificada, além da fundamentação teórica 
explicitada, pela necessidade de se constituir dados de pesquisas contextualizadas localmente, que possibilitem melhor conhecer as regiões de influência das universidades para, dessa forma, formular planejamentos e ações pedagógicas que respondam às necessidades da região.

\section{Metodologia}

É indispensável considerar a capacidade humana da memória, a qual é possível graças a um lastro neurobiológico complexo, ao qual se somam as interações socioculturais e temporais que interagem com esta constituição. Formam-se, assim, novas e complexas redes neuronais que implicam em reforçar ou não certas lembranças (Candau, 2011).

O homem tem consciência de sua memória, da sua capacidade de simbolismo e de estabelecer noções e relações de tempo, assim como tem a capacidade do esquecimento. Rememorar pode ser compreendido como uma tentativa de percorrer o caminho entre algo que supõe esquecido e o presente. O objeto rememorado, de maneira fácil ou difícil, com poucos ou mais detalhes, é visto pelos olhos do presente, pelos sentimentos do presente, pelas motivações do presente, portanto, não é um retrato fiel de algo do passado, mas, sim, uma representação. Ao trabalhar com dados da memória individual dos colaboradores da pesquisa, compreende-se que não se obtém um retrato fiel de suas experiências, pois são enquadramentos únicos de fatos passados que podem lhes chegar justamente em partes (Candau, 2002).

A partir dessa compreensão afasta-se qualquer pretensão de explicação e generalização do fenômeno investigado, e parte-se em busca de uma aproximação das lembranças do indivíduo sobre as práticas esportivas vivenciadas na escola.

Conforme Gil (2008), esta pesquisa possui natureza quantitativa e exploratória, tendo por delineamento um estudo de levantamento. Caracteriza-se pela interrogação direta do objeto que se deseja conhecer, o que envolve um grupo de pessoas com características previamente estabelecidas. Os dados obtidos foram analisados estatisticamente.

Participaram do estudo 102 acadêmicos de EF da Universidade Regional do Cariri URCA, localizada no sul do Ceará, de ambos os sexos, sendo 52 do feminino e 50 do masculino, com idade entre 17 e 35 anos, matriculados do $1^{\circ}$ ao $4^{\circ}$ semestre do referido curso. A escolha em pesquisar esse público se deu por ter ingressado recentemente na universidade, fato que leva a entender que os acadêmicos tenham lembranças recentes das suas participações no conteúdo dos esportes na EFE. A pesquisa foi realizada nas instalações da universidade onde o público se encontrava. 
Para a obtenção dos dados, os pesquisadores basearam-se no questionário sobre Vivências em Educação Física, de Etchepare e Pereira (2004), o qual foi adaptado à realidade da pesquisa em questão, sendo os dados restringidos ao conteúdo Esporte, exclusivamente no contexto da disciplina de EF. Posteriormente, para uma primeira validação, o questionário foi analisado por um professor especialista. Após análise, sugestões e modificações, o questionário foi aplicado com finalidade de correções por meio de pré-teste para melhor aproveitamento na aplicação final. O pré-teste foi realizado com alunos que não participaram da pesquisa.

A partir do pré-teste foram necessárias modificações em algumas perguntas, a fim de melhorar a compreensão por parte dos participantes da pesquisa.

O questionário totalizou 27 questões objetivas com mais de uma escolha por questão. Exemplo: 1) Você já praticou Voleibol? a) Sim, nas aulas de Educação Física na escola; b) Sim, pratiquei em outro local. Onde? ; c) Não pratiquei esse esporte; d) Ainda pratico com frequência.

Os dados foram tabulados a partir de percentuais e apresentados em gráficos com utilização do programa Excel 2010. Nos resultados da pesquisa, os gráficos foram divididos por categorias de análise, conforme a classificação dos esportes de González e Bracht (2012), sendo: a) vivências sobre os esportes de invasão na EFE; b) vivências sobre os esportes com rede divisória e parede de rebote na EFE; c) vivências sobre os esportes de combate na EFE; d) vivências sobre os esportes técnico-combinatórios na EFE; e e) vivências sobre os esportes de marca na EFE.

A exclusão de alguma categoria e/ou modalidade esportiva dentro da classificação indicada se deu devido à análise da cultura local e à predominância dos esportes destacados nos resultados (foram excluídas as categorias de esportes de campo e taco e os esportes de precisão, uma vez que não há vivência em nenhuma das modalidades dessas categorias).

Todos os sujeitos envolvidos foram esclarecidos sobre a pesquisa por meio do Termo de Consentimento Livre e Esclarecido (TCLE), sendo comunicados sobre o processo, bem como sobre os possíveis riscos e precauções na interação entre o pesquisador e o sujeito, concedendo anuência em sua participação. 


\section{Resultados e Discussão}

\subsection{Vivências sobre os esportes de invasão na Educação Física Escolar}

$\mathrm{Na}$ Figura 1, a seguir, identificou-se a prevalência de vivências esportivas na modalidade de Futsal masculino (92\%) e feminino (52\%), onde o público masculino se destacou com mais vivência. Com menores índices de vivências ficaram as modalidades esportivas de Handebol ( $72 \%$ do público masculino e $50 \%$ do público feminino), Futebol (50\% do público masculino e $27 \%$ do público feminino) e Basquetebol (40\% do público masculino e $29 \%$ do público feminino). Novamente, a prevalência da prática em todas as modalidades foi do sexo masculino. O Rúgbi foi menos vivenciado em relação às demais modalidades, e o seu acesso foi exclusivo do público feminino.

Figura 1 - Vivências sobre os esportes de invasão na Educação Física Escolar.

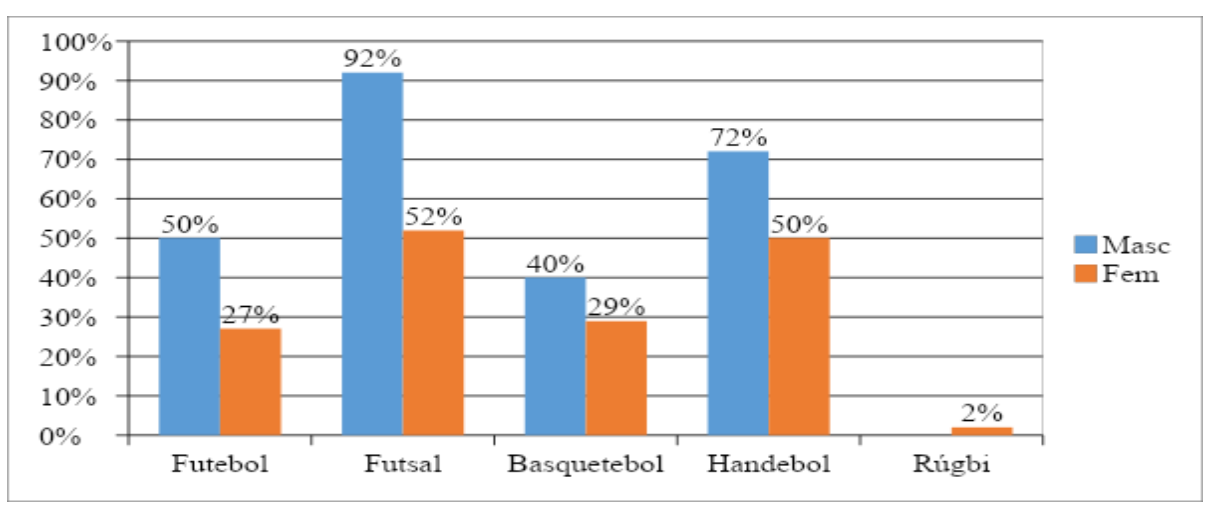

Fonte: Os autores.

O Esporte é reconhecido como o conteúdo mais difundido nas aulas de EFE. Alguns motivos influenciam essa prática: a preferência dos alunos; por ser um tema de expressão mundial; até mesmo por ser um conteúdo de maior domínio por parte do professor, etc. Há, no entanto, uma preocupação sobre a forma como esse conteúdo é oferecido nos anos de aprendizagem escolar, pois geralmente esse conhecimento sobre o esporte fica restrito a poucas modalidades, como o Futebol, o Futsal, o Voleibol, o Handebol e o Basquetebol (Betti, 1999).

A autora já demonstrava preocupação com a restrição de conteúdos na EFE, e entende que muitas podem ser as razões para justificar a presença massificada de apenas algumas modalidades, tais como: a insegurança do professor em ministrar outros conteúdos; a ausência 
do espaço físico e material adequado na escola; ou a crença de que os alunos não irão aprender outras modalidades (Betti, 1999).

O fenômeno do desinvestimento docente, contudo, pode ser um fator que perpassa esses resultados. Assim como o efeito midiático, que também interfere no desejo dos alunos e nas escolhas dos professores, além da tendência do professor enfatizar o conteúdo no qual tem mais segurança.

As evidências constatadas neste estudo compactuam com o estudo de Pereira et al. (2015) que, em uma pesquisa realizada com acadêmicos do curso de Educação Física revelou que o público masculino teve maior vivência no Futebol e no Futsal (73\%), no Handebol $(66,67 \%)$ e no Basquetebol $(60 \%)$. Na mesma pesquisa, as mulheres apresentaram maior vivência no Basquete (75\%), no Futsal e Handebol (60\%) e no Futebol (50\%).

Em outra pesquisa feita com alunos do $3^{\circ}$ ano do Ensino Médio no Rio Grande do Sul, Gattiboni et al. (2015) identificaram que as vivências nos esportes se limitavam aos coletivos, dentre eles, o Futsal $(56,6 \%)$, o Futebol $(51,3 \%)$ e o Basquetebol $(43,2 \%)$ foram os mais vivenciados.

Os resultados do estudo nesta categoria expressam vivências significativas por parte dos participantes da pesquisa em modalidades esportivas culturalmente conhecidas do repertório das aulas tradicionais de EFE, o que compactua com os estudos citados.

\subsection{Vivências sobre os esportes com rede divisória e parede de rebote na Educação}

\section{Física Escolar}

A Figura 2, a seguir, apresenta as vivências dos esportes com rede divisória e parede de rebote na escola. Os resultados indicam maior ênfase no conteúdo mais tradicional, como é o caso do Voleibol (74\% masculino e 52\% feminino), o qual é vivenciado por ambos os sexos, mantendo-se a prevalência do masculino. Percebe-se, no entanto, certa projeção de vivência no Tênis de Mesa (42\% masculino e 10\% feminino) e Peteca (26\% masculino e 27\% feminino). As vivências menos expressivas ficaram entre o Futevôlei, o Badminton e o Tênis, que são modalidades ainda incipientes na cultura da região estudada. 
Research, Society and Development, v. 9, n. 9, e119996319, 2020

(CC BY 4.0) | ISSN 2525-3409 | DOI: http://dx.doi.org/10.33448/rsd-v9i9.6319

Figura 2 - Vivências sobre os esportes com rede divisória e parede de rebote na EF Escolar.

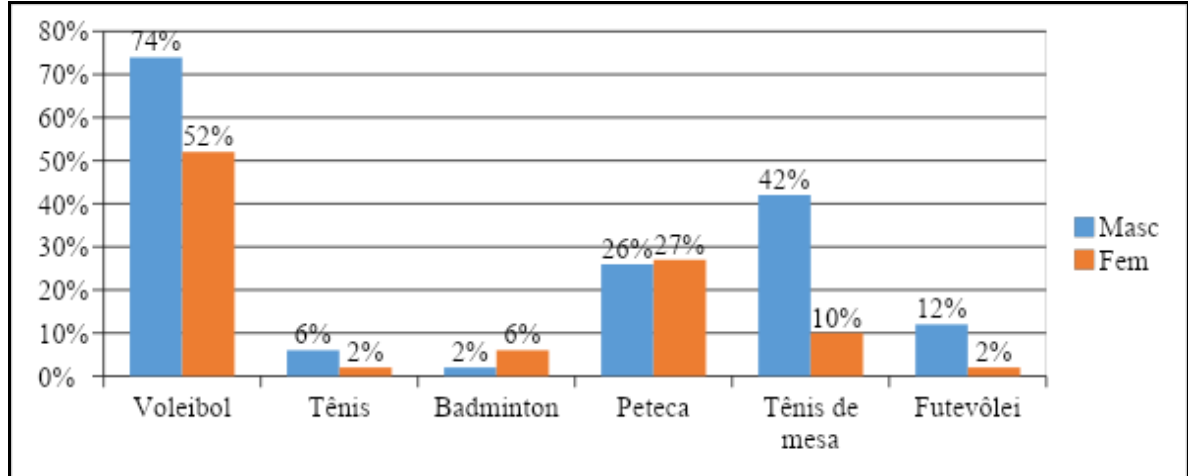

Fonte: Os autores.

Sobre o Voleibol na EFE, Mezzaroba e Pires (2011) afirmam que é a segunda modalidade mais praticada no Brasil. A Figura 2 revela que as escolas na região estudada contribuem nesse processo, tornando essa modalidade esportiva conhecida das comunidades que a frequentam.

Existem algumas condições que dificultam uma aproximação maior dos professores para lecionar modalidades não tradicionais, como as indicadas neste tópico. Uma das maiores limitações nas aulas de EFE é o espaço físico e material, como versam Gaspari et al. (2006) ao pesquisarem as dificuldades encontradas por professores de $\mathrm{EF}$ ao ingressarem na escola.

Geralmente, o espaço destinado ao professor de EFE é uma quadra/ginásio, destinados unicamente para as modalidades mais tradicionais, o que potencializa a prática do Futsal e do Voleibol até aqui analisados.

\subsection{Vivências sobre os esportes de combate na Educação Física Escolar}

Em referência à Figura 3, a seguir, que trata da categorização dos esportes de combate na EFE, os dados pontuam vivências incipientes do público pesquisado, sendo o maior indicador a vivência da Capoeira (12\% masculino e $4 \%$ feminino), em que novamente se destaca a maior vivência do público masculino. Constata-se, porém, que o Muay thai e o Jiu jitsu foram pouco vivenciados por ambos os sexos. 
Research, Society and Development, v. 9, n. 9, e119996319, 2020

(CC BY 4.0) | ISSN 2525-3409 | DOI: http://dx.doi.org/10.33448/rsd-v9i9.6319

Figura 3 - Vivências sobre os esportes de combate na EF Escolar.

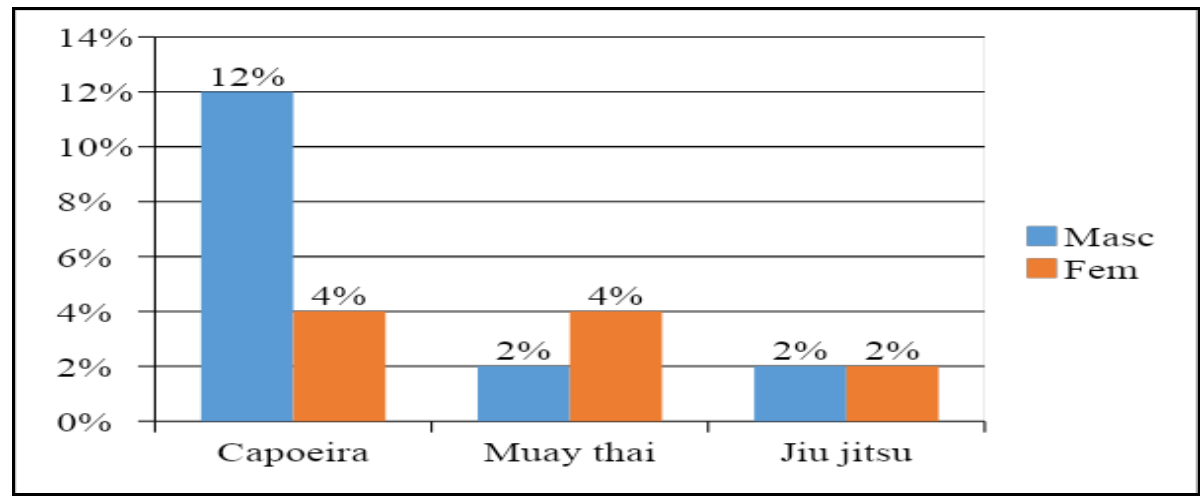

Fonte: Os autores.

A respeito deste conteúdo, Nascimento e Almeida (2007) atestam indicadores que demonstram restrições e dificuldades de ensinar o tipo de modalidade. Segundo os autores, a falta de vivência pessoal em lutas no campo pessoal e acadêmico, aliada à preocupação com a violência são fatores limitantes para a sua introdução na escola.

Nas últimas duas décadas foram produzidas metodologias para o estudo das lutas, divulgadas em livros e artigos científicos, porém, essas ainda não foram apropriadas pelos professores de EFE.

\subsection{Vivências sobre os esportes técnico-combinatórios na Educação Física Escolar}

Assim como os esportes de combate, os técnico-combinatórios (destacados na Figura 4) revelam baixo índice de vivências na escola por parte dos participantes da pesquisa. Destaca-se que a Ginástica é um conteúdo tradicional da EF, porém, não parece fazer sentido na realidade pesquisada.

Figura 4 - Vivências sobre os esportes técnico-combinatórios na EF Escolar.

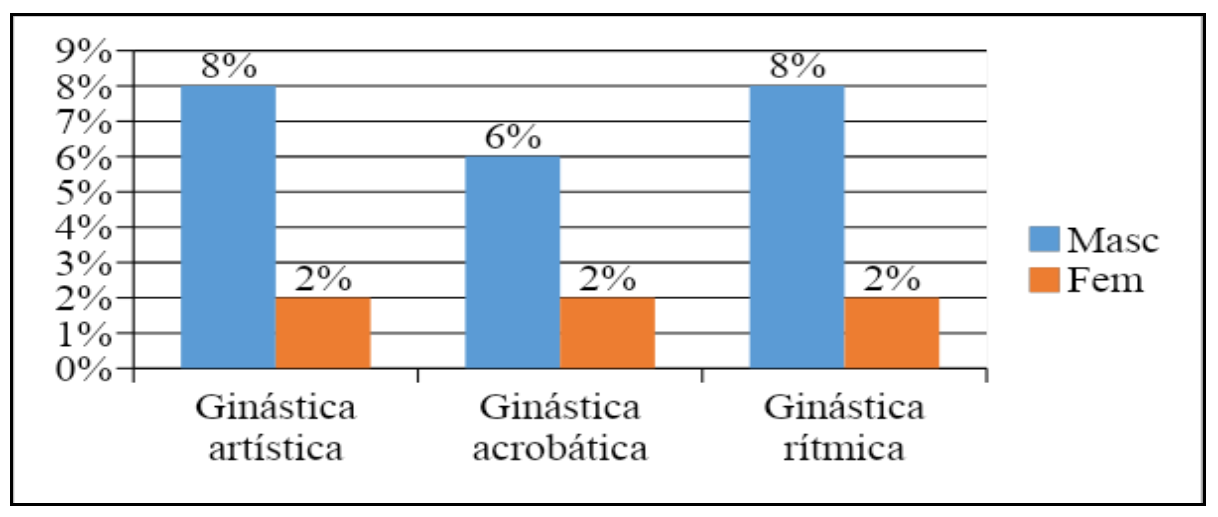

Fonte: Os autores. 
Compactuando com a ideia citada anteriormente, Schiavon e Nista-Piccolo (2007) discutem que os principais pontos que podem estar associados a pouca vivência desses esportes na escola são a formação e a realidade dos recursos do Ensino Superior, os quais diferem da realidade escolar. Por esta razão há uma série de dificuldades que colaboram para que o conhecimento dessas modalidades seja exíguo, o que é confirmado pelo Instituto Brasileiro de Geografia e Estatística (IBGE), que em 2015 constatou que apenas 3,2\% dos pesquisados praticaram Ginástica rítmica e artística (Brasil, 2015). Essa problemática passa por inúmeras situações, como: instalações inadequadas da escola, falta de materiais, limitações na formação dos professores, além de eventual abandono da EFE.

Silva e Ciasca (2020), em pesquisa realizada no Estado do Ceará, avaliaram a estrutura física de diversas escolas, e identificaram que na sua grande maioria elas possuem quadras esportivas deficitárias e, em casos mais extremos, essas nem mesmo existem. A infraestrutura, assim como o investimento material e de professorado, são aspectos fundamentais para haver um ensino de Educação Física Escolar digno e diverso, situação esperada do ensino do conteúdo dos Esportes e outros.

\subsection{Vivências sobre os esportes de marca na Educação Física Escolar}

A Figura 5, a seguir, indica que as modalidades na categoria dos Esportes de Marca também foram pouco praticadas.

Figura 5 - Vivências sobre os esportes de marca na EF Escolar.

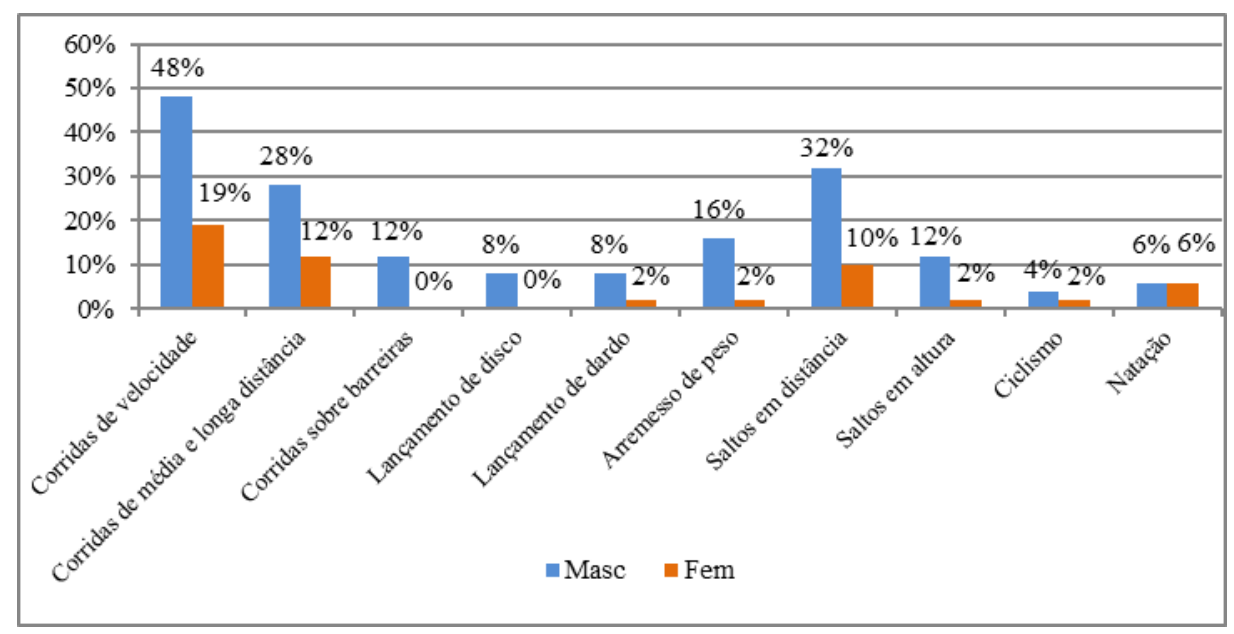

Fonte: Os autores. 
As modalidades do Atletismo são as mais praticadas, dentre as quais se destaca a Corrida de Velocidade como a mais vivenciada por ambos os sexos (48\% para o masculino e 19\% para o feminino). Em seguida, constam as modalidades de Salto em distância e Corrida de média e longa distância. Com menor ênfase estão as modalidades de Corrida sobre barreiras, Lançamento de disco, Lançamento de dardo e Arremesso de peso, todas praticadas principalmente por homens.

A Corrida de velocidade e a Corrida de média e longa distância, modalidades individuais do Atletismo, não necessitam de muitos recursos, geralmente apenas de um espaço demarcado e uma base de apoio na largada. Já as outras modalidades do Atletismo requerem materiais específicos, além do espaço. A Natação e o Ciclismo já necessitam de um investimento financeiro maior, logo, as vivências nessas modalidades são mínimas, e foram pouco praticadas da EFE.

Em estudo similar, Pereira et al. (2015) destacaram que 53,3\% dos homens afirmaram ter vivenciado Corrida de velocidade na escola, seguido de 46,67\% em Salto em distância e $20 \%$ em Corrida sobre barreiras. As vivências do sexo feminino apontaram que 50\% tiveram vivências em Corrida de velocidade, além de 35\% em Salto em distância e 10\% em Corrida sobre barreiras.

Ao pesquisar a percepção dos acadêmicos de Educação Física quanto à experiência nas provas do Atletismo na escola, Mezzaroba et al. (2006) identificaram que a grande maioria dos acadêmicos salientaram as modalidades como relevante objeto de aplicação nas aulas. Afirmaram, no entanto, que nem todos os professores sentem motivação para lecionar esses conhecimentos, uma vez que não tiveram participação pessoal na modalidade, ou por sua formação acadêmica não ter vislumbrado de maneira ampla as modalidades do Atletismo.

Segundo levantamento do IBGE, de 2015, quanto menor o nível de instrução formal, menor o percentual de vivência nos esportes, o que é comprovado pelos dados apresentados, os quais revelam que $82 \%$ dos brasileiros sem instrução não praticam qualquer esporte. Esse perfil decresce para 63,4\% entre aqueles que têm o Ensino Fundamental completo, e recua para 43,3\% para quem têm o Ensino Superior completo. De certa forma, isso demonstra que a escola pode ser um significativo fator influenciador da adesão a práticas esportivas (Brasil, 2015).

Outro fator que merece destaque é a tímida vivência dos esportes pelas mulheres. Segundo o mesmo levantamento do IBGE, a cada três mulheres, duas não praticam esportes ou qualquer atividade física (Brasil, 2015). 
Os dados apresentados e discutidos no presente estudo sobre as vivências esportivas de acadêmicos de EF também retratam essa realidade, ou seja, há superioridade no quesito prática pelo público masculino nas vivências esportivas no âmbito escolar.

Para efeito desta análise cabe enfatizar que nem sempre há o acesso igualitário das práticas corporais esportivas para ambos os sexos, ou seja, a disparidade cultural entre homens e mulheres é caracterizada também dentro do esporte, afinal, feminino e masculino ocupam espaços diferentes em termos de poder. $\mathrm{O}$ masculino geralmente está associado às razões de força, atividade e racionalidade, princípios que cabem no esporte, enquanto o feminino é relativo às condições domésticas, de fragilidade e emoções (Souza \& Knijnik, 2007).

Segundo Goellner (2005), a diferença de gêneros pode ser observada em diferentes instâncias de conhecimento do esporte, especialmente em práticas esportivas nos clubes, nas atividades escolares, nas áreas de lazer, na presença nos estádios e ginásios e nos meios de comunicação de massa.

No contexto da EF Escolar também é possível perceber divisões ou exclusão entre gêneros nas práticas esportivas, cuja proposição pode ser mediada pelos professores, fazendo com que a escola se torne protagonista no acesso a esse conhecimento de forma ampla e igualitária.

Preocupa a incoerência existente entre a extensa produção crítica na área de estudos da EFE e a pouca materialização desses estudos no âmbito escolar, principalmente no contexto local no qual este estudo foi realizado.

\section{Considerações Finais}

O estudo mostrou que, embora o conteúdo dos esportes seja o mais utilizado nas aulas de EF, os participantes da pesquisa não estudaram a diversidade contida no tema durante a escolaridade básica. A prática ficou restrita aos esportes de interação com adversário e somente a dois subtemas dessa categoria, ou seja, os esportes de Invasão e os de Rede Divisória, com predominância significativa de apenas um tipo de modalidade dentro de cada grupo: Futsal e Voleibol.

As experiências com outros tipos de esportes não foram significativas, o que denota um caráter reducionista dos conteúdos da EF no currículo do contexto pesquisado. Da mesma forma, há disparidade de acesso ao conhecimento entre meninos e meninas. Os resultados 
referidos ao contexto sociocultural investigado não permitem afirmar que a instituição escola seja ativa no que diz respeito à transmissão do legado cultural e diversificado do esporte.

Tal constatação indica limitações na introdução de crianças, adolescentes, jovens e adultos em diversas manifestações da cultura corporal de movimento e, consequentemente, na sua condução à ampliação de compreensões acerca dessa dimensão da cultura humana, potencializando o seu usufruto.

A pesquisa é um estado permanente do professor que pensa o seu contexto de atuação. Assim sendo, aposta-se no objetivo de que a soma de estudos contextualizados possa fazer sentido às comunidades no que diz respeito ao subsídio da intervenção pedagógica para a melhoria das condições de oferta e condução do trabalho com a EFE. Somente assim será possível torná-la uma disciplina que efetivamente colabore num projeto de formação humana, que tenha como premissa a identificação, o acesso, a compreensão e o usufruto da pluralidade da cultura corporal de movimento que constitui a atual sociedade.

Entende-se que a EFE tem a responsabilidade apontada neste estudo, e que cabe desenvolver programas de extensão universitária e ou estudos do tipo pesquisa-ação que ampliem as experiências das comunidades quanto à prática esportiva, contribuindo para além da apropriação de modalidades esportivas, também para a apropriação e elaboração de metodologias de ensino.

\section{Referências}

Betti, I. C. R. (1999). Esporte na escola: mas é só isso, professor? Revista Motriz. Rio Claro, 1(1), 25-31. Recuperado de http://files.cursoeducacaofisica.webnode.com/20000008860238611e0/ESPORTE\%20NA\%20ESCOLA\%20-\%20IRENE\%20RANGEL.pdf.

Bracht, V., Faria, B. A., Moraes, C. E. A., Fernandes, E. S., Almeida, F. Q., Ghidetti, F. F., Gomes, I. M., Rocha, M. C., Machado, T. S., Almeida, U. R., \& Penha, V. M. (2012). A Educação Física Escolar como tema da produção do conhecimento nos periódicos da área no Brasil (1980-2010): parte II. Revista Movimento, 18(2), 11-37. doi: 10.22456/19828918.30158.

Brandão, C. R. (1981). O que é educação. São Paulo: Brasiliense.

Brasil. Ministério do Planejamento, Orçamento e Gestão. Instituto Brasileiro de Geografia e 
Estatística (2015). Pesquisa Nacional por Amostras de Domicílios. Rio de Janeiro. Recuperado de: http://www.valor.com.br/brasil/4971304/ibge-maioria-dos-brasileiros-esedentaria-partir-da-adolescencia.

Candau, J. (2002). Antropología de la memória. Buenos Aires: Nueva Visión.

Candau, J. (2011). Memória e identidade (5 $5^{\mathrm{a}}$ ed). São Paulo: Contexto.

Carlan, P. (2012). O esporte como conteúdo da educação física escolar: um estudo de caso de uma prática pedagógica. 354 f. Tese (doutorado em Educação Física). Universidade Federal de Santa Catarina. Florianópolis.

Carlan, P., Kunz, E., \& Fensterseifer, P. E. (2012). O esporte como conteúdo da Educação Física escolar: estudo de caso de uma prática pedagógica "inovadora". Revista Movimento, 18(4), 55-75. Recuperado de: https://seer.ufrgs.br/Movimento/article/view File/29643/23448.

Cortela, M. S. (1997). A escola e o conhecimento: reflexão sobre fundamentos epistemológicos e políticos dessa relação. 1997. 151 f. Tese (Doutorado em Educação). Pontifícia Universidade Católica, São Paulo.

Darido, S. C. (2012). Educação Física na escola: realidade, aspectos legais e possibilidades. In: Darido, S. C. (Coord.). Caderno de formação: formação de professores didática dos conteúdos. São Paulo: Cultura Acadêmica.

Darido, S. C., \& Sanchez Neto, L. (2005). O contexto da Educação Física na Escola. In: Darido, S. C., \& Rangel, I. C. A. (Coords.). Educação física na escola: implicações para a prática pedagógica. Rio de Janeiro: Guanabara Koogan.

Etchepare, L. S., \& Pereira, E. F. (2004). Proposta de validação de um instrumento para avaliação de vivências em educação física. Revista Digital, 10(77), 1-1. Disponível em: https://www.efdeportes.com/efd77/avalia.htm. 
Fensterseifer, P. E., \& Silva, M. A. (2011). Ensaiando o "novo" em Educação Física escolar: a perspectiva de seus atores. Rev. Bras. Ciênc. Esporte, 33(1), 119-134. Recuperado de: http://revista.cbce.org.br/index.php/RBCE/article/view/874.

Gaspari, T. C., Souza Júnior, O., Maciel, V., Impolcetto, F. M., Venâncio, L., Iorio, L., Thommazo, A., \& Darido, S. C. (2006). A realidade dos professores de Educação Física na escola: suas dificuldades e sugestões. Revista Mineira de Educação Física, 14(1), 109-137.

Gattiboni, B. D., Sá, A. S., Pozzobon, D., Borges, L. L., Denardini, V. W., Bevilacqua, L. A., Balsan, L. A., G. \& Daronco, L. S. E. (2015). Vivências esportivas e percepção da imagem corporal dos adolescentes do Ensino Médio de escolas privadas. Salusvita, 34(1), 13-26. Recuperadi de https://pdfs.semanticscholar.org/579d/a9bd88aa73868ef50b42a32 39e308df999d8.pdf.

Gil, A. C. (2008). Métodos e técnicas de pesquisa social. São Paulo: Atlas.

Goellner, S. V. (2005). Mulher e esporte no Brasil: entre incentivos e interdições elas fazem história. Revista Pensar a Prática, 1(1), 85-100. doi: https://doi.org/10.5216/rpp.v8i1. 106.

González, F. J., \& Bracht, V. (2012). Metodologia do ensino dos esportes coletivos. Vitória: UFES, Núcleo de Educação Aberta e a Distância.

González, F. J., Bracht, V., Caparroz, F. E., \& Fensterseifer, P. E. (2014). Sentidos e significados do ensino do esporte na Educação Física escolar: deslocamentos históricos e proposições contemporâneas. In: Marinho, A., Nascimento, J. V., \& Oliveira, A. A. B (Orgs.). Legados do esporte brasileiro (pp. 121-162). Florianópolis: Ed. da UDESC.

González, F. J., \& Fensterseifer, P. E. (2009). Entre o "não mais” e o "ainda não": pensando saídas do não lugar da EF escolar I. Cadernos de Formação RBCE, 1(1), 9-24. Recuperado de: http://revista.cbce.org.br/index.php/cadernos/article/view/929.

González, F. J., \& Fensterseifer, P. E. (2010). Entre o "não mais" e o “ainda não": pensando saídas do não-lugar da Educação Física escolar II. Revista Brasileira de Ciências do Esporte, 1(2), 10-21. Recuperado de: http://revista.cbce.org.br/index.php/cadernos/article/view/929. 
González, F. J., \& Fraga, A. B. (2012). Afazeres da Educação Física na escola: planejar, ensinar, partilhar. Erechim: Edelbra.

Kunz, E. (2004). Transformação didático-pedagógica do esporte. Ijuí, RS: Ed. Unijuí.

Machado, T. S., Bracht, V., Faria, B. A., Moraes, C., Almeida, U., \& Almeida, F. Q. (2010). As práticas de desinvestimento pedagógico na Educação Física escolar. Revista Movimento, 16(2), 129-147. Recuperado de: http://reiipefe.com/wp-content/uploads/ 2015/12/ Desinvestimento-1.pdf.

Magalhães, A. C. (2018). Entre o "não mais" e o "ainda não" a armadilha do "talvez, quem sabe": a Educação Física da escola no jogo da economia do discurso. Arquivos em Movimento, 14(2), 85-99. Recuperado de: https://revistas.ufrj.br/index.php/am/ article/view/19325/pdf.

Mezzaroba, C., \& Pires, G. L. (2011). Breve panorama histórico do voleibol: do seu surgimento à espetacularização esportiva. Revista de Educação Física, 2(2), 3-19. Recuperado de: https://refisica.uea.emnuvens.com.br/refisica/article/view/16.

Mezzaroba, C., Romansini, L. A., Moreira, E. L., Pereira, H., \& Souza, E. R. (2006). Visão dos acadêmicos de Educação Física quanto ao ensino do Atletismo na escola. Esportes.universoef.com.br. Recuperado de: http://esportes.universoef.com.br/container/ gerenciador_de_arquivos/arquivos/371/a-visao-dos-academicos.pdf.

Nascimento, P. R. B., \& Almeida, L. (2007). A tematização das lutas na Educação Física Escolar: restrições e possibilidades. Revista Movimento, 13(3), 01-20. doi: 10.22456/19828918.3567.

Pereira, E. F., Andrade, R. D., Teixeira, C. S., Daronco, L. S. E., \& Paim, M. C. C. (2015). Vivências em Educação Física e esportes dos acadêmicos que ingressam no curso de Educação Física: uma perspectiva de gênero. Revista Brasileira de Ciência e Movimento, 1(23), 126-135. doi: 10.18511/0103-1716/rbcm.v23n1p126-135. 
PNUD. Programa das Nações Unidas para o Desenvolvimento (2017). Programa das Nações

Unidas para o Desenvolvimento no Brasil. Recuperado de: http://www.br.undp.org/ content/brazil/pt/home/.

Schiavon, L., \& Nista-Piccolo, V. L. (2007). A ginástica vai à escola. Revista Movimento, 13(3), 131-150. doi: 10.22456/1982-8918.3572.

Silva, L. M., \& Ciasca, M. I. F. L. (2020). Estrutura física escolar como fator determinante da qualidade da educação em escolas profissionais do Ceará: entre a realidade e o mito. Research, Society and Development, 9(7), 1-20. doi: 10.33448/rsd-v9i7.4634.

Souza, J. S. S., \& Knijnik, D. J. (2007). A mulher invisível: gênero e esporte em um dos maiores jornais diários do Brasil. Revista Brasileira de Educação Física e Esporte, 21(1), 3548. doi: 10.1590/S1807-55092007000100004.

Souza, S., Barbosa do Nascimento, P. R., \& Fensterseifer, P.E. (2018). Atuação docente em Educação Física escolar: entre investimento e desinvestimento pedagógico. Motrivivência, 30(54), 143-159. doi: 10.5007/2175-8042.2018v30n54p143.

\title{
Porcentagem de contribuição de cada autor no manuscrito
}

\author{
João Márcio Fialho Sampaio - 40\% \\ José Cícero Cabral de Lima Júnior - 10\% \\ Paulo Rogério Barbosa do Nascimento - 20\% \\ Lucas Vieira de Lima Silva - 10\% \\ Janayna Samara Alves da Silva - 5\% \\ Samara Mendes de Sousa - 5\% \\ Lázaro Ranieri de Macêdo - 5\% \\ Cleiton Félix de Sousa - 5\%
}

